\title{
Are Saudi Banks Efficient? Evidence Using Data Envelopment Analysis (DEA)
}

\author{
Khalid AlKhathlan (Corresponding Author) \\ Economics Department, College of Business Administration, King Saud University \\ P.O.Box 2459, Riyadh 11451, Saudi Arabia \\ Phone No. 00966-555-227217, Email: kaa8161@hotmail.com
}

Syed Abdul Malik

Finance Department, College of Business Administration in Al kharj, King Saud University

P.O.Box 2459, Riyadh 11451, Saudi Arabia

\begin{abstract}
Saudi Arabia has a bank-centric and diverse financial system compared with other countries in the region. This paper uses basic DEA models i.e. CCR and BCR to evaluate the relative efficiency of Saudi Banks using annual data from 2003 through 2008. The results show that, on a relative scale, Saudi banks were efficient in the management of their financial resources. In addition, the results would provide crucial information about Saudi banks' financial conditions and management performance for the benefit of bank regulators, managers and bank stock investors.
\end{abstract}

Keywords: Saudi Banking Efficiency, Saudi Financial System, data Envelopment Analysis, Technical Efficiency, Scale Efficiency

\section{Introduction}

In its Forty-Fourth Annual Report the Saudi Arabian Monetary Agency-SAMA (2008, pg. 51) summarized the performance of Saudi banks as follows:

"Commercial banks recorded good growth rates in their financial positions during 2007. This was due to efficient management by commercial banks of their financial resources."

This paper gives the quantitative proof of the above summarized view of SAMA and investigates the relative efficiency of Saudi banks during the period of 2003-2008 by using the Data Envelopment Analysis (DEA) technique. Over the past two decades, DEA has become a popular methodology for evaluating the relative efficiencies of decision making units (DMUs). A DMU is an entity that produces outputs and uses up inputs, in this study, each bank constitutes a DMU.

DEA is a linear programming model that measures the efficiency of DMUs in multiple-inputs, multiple-outputs setting. Typically, each of the DMUs in a given population use the same multiple inputs in varying quantities to produce varying quantities of the same multiple outputs. Using the actual observed values for the inputs and outputs for each DMU, DEA constructs a piecewise linear production surface, which in economic terms represents the revealed best-practice production frontier - the maximum output empirically obtainable for any DMU in the observed population, given its level of inputs. By projecting each unit onto the frontier, it is possible to determine the level of inefficiency by comparison to a single reference unit or a convex combination of other reference units. The projection refers to a hypothetical DMU which is a convex combination of one or more efficient DMUs and not an actual DMU. Efficient DMUs typically utilize the same level of inputs and produce the same level or higher of outputs.

Although DEA models jointly handle the multiple inputs and multiple outputs characteristic of financial services, they have several limitations. First, with the basic DEA models there are usually a large number of zero weights in inputs and outputs variables. Second, the inclusion of a large number of inputs and outputs reduces the degrees of freedom of this program and, as a result, the number of efficient units increases.

To the researcher's best knowledge, this is the first time this technique is being used to analyze both the technical and scale efficiencies of Saudi banks using two basic DEA models. The results would provide us explicit indications as to whether the Saudi banks are efficient as claimed by SAMA even in the wake of global melt down. In addition, the results would provide crucial information about Saudi banks' financial conditions and management performance for the benefit of bank regulators, managers and bank stock investors. 
The paper is divided into five parts. Following this, Section two review briefly the previous studies on bank frontier efficiency in Arab World. Section three proceeds with the methodology and data used to carry out the efficiency analysis. Section four examines the empirical findings and section five concludes the paper.

\section{Literature Review}

Empirical evidence on performance evaluation and efficiency of the banking industry is much researched globally. However, there is dearth of research in the Arab world. The earliest technique, used to measure performance changes was ratio analysis which examines the financial statements of individual firms and comparing them with a benchmark. However, this technique failed to take into account the fact that banks produce multiple outputs from multiple inputs and consistent aggregation was not possible (See, for example, Barnes, 1987; Smith, 1990). The short comings of such a descriptive and static analysis of the data are overcome by later researchers with the use of parametric and non-parametric techniques.

The parametric and non-parametric techniques differ mainly in how they handle random error and their assumptions regarding the shape of the efficient frontier. The three main parametric (or econometric) methodologies used by researches to examine financial institutions include the stochastic frontier analysis, the thick frontier analysis, and the distribution free analysis. In general, the parametric approaches specify a functional form for the cost, profit, or production relationship among inputs, outputs and environmental factors, and allow for random error.

The two non-parametric (or mathematical programming) techniques used in the banking sector efficiency literature includes Data Envelopment Analysis (DEA) and Malmquist Productivity Indices (MPI). In general, a non-parametric technique does not require the specification of an a priori functional form and therefore is the most favored approach.

The literature examining the efficiency of financial institutions with parametric and/or nonparametric frontier techniques has expanded rapidly in recent times. While, a large body of literature spanning a half-century exists on banking efficiency in the United States (see surveys in Berger et al., 1993; Berger and Humphrey, 1997; and Berger, 2007), more recent studies examine several other countries such as India (Ataullah and Le, 2006), Hong Kong (Drake et al., 2006), Singapore (Sufian, 2007), Croatia (Jemric and Vujcic, 2007), Turkey (Isik, 2008), Ukraine (Kyj and Isik, 2008), and Thailand (Supachet Chansarn, 2008). What follows is a brief exposition on empirical research on bank frontier efficiency in Arab world.

Al-Faraj et al. (1993) evaluated the relative efficiency of 15 bank branches of one of the largest commercial banks in the eastern province of Saudi Arabia by means of DEA. Using one year data he found out that 12 branches were efficient based on eight inputs and seven outputs identified.

Al-Shammari and Salimi (1998) evaluated the comparative operating efficiency of banks in Jordan using a modified version of DEA. The results suggest that the majority of banks investigated are fairly inefficient over the period 1991-1994.

Hassan et al. (2004) employing a panel of 31 banks for the years 1998 and 2000 investigated relative efficiency of the banking industry in Bahrain. The results indicate that all banks have improved their efficiency levels and experienced some gains in productivity.

Al-Faraj et al. (2006) investigated the performance of the Saudi commercial banking industry using DEA to evaluate the technical efficiency of Saudi banks for the year 2002 and compared with world mean efficiency scores. Their study revealed that the mean efficiency score of Saudi commercial banks compares very well with the world mean efficiency scores. They recommends that Saudi banks should continue their efforts of adapting new technologies and providing more services in order to sustain competitive advantages as Saudi Arabia continues to deregulate the banking industry.

Saeed Al-Muharrami (2007) examined productivity changes in the countries of the Gulf Cooperation Council (GCC) banks using Malmquist DEA. The results indicated a negative change in efficiency during the period from 1993 to 2002 for the 52 GCC banks considered. Further, they found that the decreased efficiency was the due to "catching up effect".

Mostafa, M. M. (2007) investigated the efficiency of top 85 Arab banks using DEA and Neural networks for the year 2005. He found that, eight banks as per the CCR Score and four banks as per BCC Score were positioned on the efficient frontier. He suggested that future studies should test the existence of positive rank-order correlations between efficiency scores obtained from DEA analysis and traditional efficiency measures such as financial ratios. His results further demonstrate that, Al-Rajhi Bank and National Commercial Bank were placed among the top ten Arab banks with a relative ranking of eight and ten respectively. 
Emrouznejad, A. and Anouze, A.L. (2009) found only six banks positioned on the efficient frontier as per the CCR Score using the same set of banks and the same set of input output variables as in Mostafa (2007). Their findings indicate that the efficiency of Arab banks reported in Mostafa (2007) is incorrect. In summary, their study overcomes with some data and methodology issues in measuring efficiency of Arab banks and highlights the importance of encouraging increased efficiency throughout the banking industry in the Arab world using the new results. Interestingly, their results also demonstrate that, Al-Rajhi Bank and National Commercial Bank were placed among the top ten Arab banks but with a new relative ranking of six and seven respectively.

The above review revealed that there is hardly any comprehensive study on measuring the efficiency of Saudi commercial banks. Thus, this study adds to the existing literature and evades previous empirical test limitations in the following way. First, the fact that despite the substantial structural changes and importance of the Saudi Arabian banking sector, the sector has remained under researched compared to studies in other countries. The present study thus addresses an important gap in the literature.

Second, compared to earlier papers, this study has the following merits. Firstly, unlike Saeed Al-Muharrami (2007), Mostafa, M. M. (2007), and Emrouznejad, A. \& Anouze, A.L. (2009) investigated GCC or top Arab banks efficiency where as we investigate the efficiency of Saudi commercial banks. Although, Al-Faraj et al. (2006) investigated technical efficiency of Saudi banks using 2002 data, our study investigates both technical and scale efficiency of Saudi commercial banks during the period 2003-08.

Lastly, the study has important public policy implications to achieve a more competitive and efficient financial system. The study could help the regulatory authorities in determining the future course of action to be pursued to further strengthen the Saudi Arabian banking sector in particular the domestic incorporated banks.

\section{Data \& Methodology}

\subsection{Data}

We use consolidated annual data compiled mainly from balance sheet and income statements of banks, their websites, and related web pages of Saudi stock exchange (Tadawul) and Saudi Arabian Monetary Agency (SAMA) on the internet. We cover only ten out of twelve commercial banks operating in Saudi Arabia which are as follows:

Arab National Bank

Al-Rajhi Bank

ANB

Bank Al-Jazira

$\mathrm{ARB}$

Banque-Saudi Fransi

BAJ

National Commercial Bank

$\mathrm{BSF}$

Riyadh Bank

$\mathrm{NCB}$

Saudi British Bank

RYB

Samba Financial Group

SABB

Saudi-Hollandi Bank

SAMBA

Saudi Investment Bank

SHB

\subsection{Methodology}

SIB

We apply two basic Data Envelopment Analysis (DEA) models i.e. Charnes-Cooper-Rhodes (CCR) model and Banker-Charnes-Cooper (BCC) model to evaluate the relative efficiency of Saudi Banks using annual data from 2003 through 2008.

\subsubsection{CCR Model}

Charnes, Cooper and Rhodes (1978) have coined the term data envelopment analysis (DEA). They extended Farrell (1957) piecewise-linear convex hull approach to frontier estimation by expanding multiple inputs and single output to multiple inputs and multiple outputs and utilized linear combination to convert it to single virtual input and output. Their model assumed constant returns to scale (CRS) to measure the relative efficiency of each DMU which is between 0 and 1 and can determine whether a DMU is in constant, increasing or decreasing returns to scale. Following, Emrouznejad, A. and Anouze, A.L. (2009), the linear programming formulation is as follows:

Minimize $\theta$

Subject to: 


$$
\begin{array}{ll}
\sum_{s} \lambda_{s} I_{s x}-\vartheta I_{k x} \leq 0 & \forall \text { inputs X } \\
\sum_{s} \lambda_{s} O_{s x}-O_{k x} \geq 0 & \forall \text { outputs y } \\
\lambda_{s} \geq 0 \quad \forall \mathrm{s} &
\end{array}
$$

The value of $\theta$ obtained will be the efficiency score for the i-th DMU.

\subsubsection{BCC Model}

Banker, Charnes and Cooper (1984) widened the CCR model to account for variable returns to scale (VRS). The CRS linear programming problem can be easily modified to account for VRS by adding the following constraints to above model:

$\sum_{s} \lambda_{s}=1$

This approach forms a convex hull of intersecting planes which envelope the data points more tightly than the CRS conical hull and thus provides technical efficiency scores which are greater than or equal to those obtained using the CRS model.

Based on the literature review we found that there is no uniform opinion concerning what constitutes inputs and outputs for banks in the context of a DEA study. We employed the intermediation approach which views banks to intermediate savings to productive investment through the supply of credit to businesses and consumers. Based on this approach, the input variables used in this study are operating expenses, equity capital, and deposits where as loans and advances (net) is the only output variable considered.

We ran the DEA model separately for each year using input-orientation. By running these programs with the same data under constant returns-to-scale (CRS) and variable returns-to-scale (VRS) assumptions, measures of overall technical efficiency $(E)$ and 'pure' technical efficiency $(P T)$ are obtained. In order to obtain a measure of scale efficiency $(S)$, we divide overall technical efficiency $(E)$ by pure technical efficiency. The following section discuses the results obtained

\section{Results}

DEA efficiency scores based on constant returns to scale (CCR Model) are shown in Table 1. Average technical efficiency in the Saudi banks during the study period ranges from 0.81913 (2003) to 0.86784 (2008). ARB and BSF were the only two banks with efficiency scores of 1.0000 each year, implying that they are on the efficiency frontier and were peers (or bench marked) during the study period. In 2007, five banks emerged on the efficient frontier, indicating efficient management by $50 \%$ of Saudi banks of their financial resources. Although, BAJ, $\mathrm{NCB}$, and SIB are having efficiency scores less than 0.75 indicating that 30 per cent of Saudi banks are inefficient and requires further probing.

\section{Insert Table 1 Here}

Table 2 shows DEA efficiency scores based on variable returns to scale (BCC Model) for each year. Mean efficiency in the Saudi banks during the study period ranges from 0.87879 (2003) to 0.95336 (2004). ARB, BAJ, and BSF were the only three banks with efficiency scores of 1.0000 each year, implying that they are on the efficiency frontier and were peers (or bench marked) during the study period. In 2006 and 2007, six banks emerged on the efficient frontier, indicating efficient management by majority $(60 \%)$ of Saudi banks of their financial resources. Although, NCB with efficiency score of 0.62319 was still inefficient during the year 2007.

Insert Table 2 Here

Table 3 shows the mean efficiency each year by decomposing technical efficiency into pure technical efficiency and scale efficiency. Decomposing technical efficiency into pure technical efficiency and scale efficiency allows us to gain insight into the main sources of inefficiencies. The average index of technical efficiency during the study period varies in between $81.91 \%$ to $86.78 \%$, of pure technical efficiency varying at $87.88 \%$ to $95.34 \%$, and of scale efficiency varying at $89.16 \%$ to $93.55 \%$.

Insert Table 3 Here

\section{Conclusion}

This paper uses the two basic Data Envelopment Analysis (DEA) models i.e. CCR and BCR to investigate and provide the quantitative proof to the claims of Saudi Arabian Monetary Agency about the efficient management of financial resources by Saudi banks. The empirical results do confirm that majority of Saudi banks efficiently managed their financial resources and the mean efficiency during the year 2007 was $86.17 \%$ and $93.97 \%$ as per 
CCR and BCR approach respectively. In 2007, we found that five banks as per the CCR Score and six banks as per BCC Score were positioned on the efficient frontier.

The empirical results indicate that ARB and BSF should be benchmarked or peer to other Saudi banks as they were the only banks found to be on the efficient frontier using both CCR and BCR models. NCB being the only bank found to be less efficient compared to the other banks in terms of CCR and BCR models.

\section{References}

Al-Faraj, T., Alidi, A. \& Bu-Bshait, K. (1993). Evaluation of bank branches by means of data envelopment analysis. International Journal of Operations \& Production Management, 13, 45-52.

Al-Faraj, T., Bu-Bshait, K. \& Al-Muhammad, W. (2006). Evaluating the efficiency of Saudi commercial banks using data envelopment analysis. International Journal of Financial Services Management, 1(4), $466-477$.

Al-Shammari, M. \& Salimi, A. (1998). Modeling the operating efficiency of banks: A nonparametric methodology. Logistics Information Management, 11, 5-12.

Al-Sharkas A, Hassan MK, Lawrence S. (2008). The impact of mergers and acquisitions on the efficiency of the U.S. banking industry: further evidence. Journal of Business, Finance and Accounting, 35: 50-70.

Ataullah A, Le H. (2006). Economic reforms and bank efficiency in developing countries: the case of the Indian banking industry. Applied Financial Economics, 16: 653-663.

Banker, R., Charnes, A. \& Cooper, W. (1984). Some models for estimating technical and scale inefficiencies in data envelopment analysis. Management Science, 30, 1078-1092.

Banxia Frontier Analyst User Guide (2001). Frontier analyst professional (Version 3.0). Glasgow, UK: Banxia Holdings Ltd.

Berger AN, Humphrey DB. (1997). Efficiency of financial institutions: international survey and directions for future research. European Journal of Operational Research 98: 175-212.

Berger AN. (2007). International comparisons of banking efficiency. Financial Markets, Institutions and Instruments 16: 119-144.

Charnes, A., Cooper, W. \& Rhodes, E. (1978). Measuring the efficiency of decision-making units. European Journal of Operational Research, 2, 429-444.

Drake L, Hall MJB, Simper R. (2006). The impact of macroeconomic and regulatory factors on bank efficiency: a non-parametric analysis of Hong Kong's banking system. Journal of Banking and Finance, 30(5): 1443-1466.

Emrouznejad, Ali and Anouze, A.L. (2009). Expert Systems with Applications, 36, 5741-5744.

Isik, I., \& Hassan, M. (2002). Technical, scale and allocative efficiencies of Turkish banking industry. Journal of Banking and Finance, 26, 719-766.

Isik I. (2008). Productivity, technology and efficiency of de novo banks: a counter evidence from Turkey. Journal of Multinational Financial Management 18(5): 427-442.

Jemric I. \& Vujcic B. (2007). Efficiency of banks in Croatia: a DEA approach. Comparative Economic Studies 44: $169-193$.

Mostafa, M. M. (2007). Modeling the efficiency of top Arab banks: A DEA-neural network approach. Expert Systems with Applications 36: 309-320 .

Sufian F. (2007). Trends in the efficiency of Singapore's commercial banking groups: a non-stochastic frontier DEA window analysis approach. International Journal of Productivity and Performance Management 56: 99-136.

$44^{\text {th }}$ Annual Report, Saudi Arabian Monetary Agency, 2008. 
Table 1.

\begin{tabular}{|c|l|c|c|c|c|c|c|}
\hline \multirow{2}{*}{ DMU No. } & \multirow{2}{*}{$\begin{array}{c}\text { DMU } \\
\text { Name }\end{array}$} & \multicolumn{7}{|c|}{ Input-Oriented CRS Efficiency } \\
\cline { 3 - 8 } & ANB & $\mathbf{2 0 0 3}$ & $\mathbf{2 0 0 4}$ & $\mathbf{2 0 0 5}$ & $\mathbf{2 0 0 6}$ & $\mathbf{2 0 0 7}$ & $\mathbf{2 0 0 8}$ \\
\hline 1 & ANB & 0.68215 & 0.93401 & 0.94741 & 1.00000 & 1.00000 & 0.96705 \\
\hline 2 & ARB & 1.00000 & 1.00000 & 1.00000 & 1.00000 & 1.00000 & 1.00000 \\
\hline 3 & BAJ & 0.71441 & 0.62352 & 0.58609 & 0.48448 & 0.55842 & 0.60983 \\
\hline 4 & BSF & 1.00000 & 1.00000 & 1.00000 & 1.00000 & 1.00000 & 1.00000 \\
\hline 5 & NCB & 0.77912 & 0.75986 & 0.76404 & 0.64942 & 0.61297 & 0.64264 \\
\hline 6 & RYB & 0.63118 & 0.73445 & 0.79837 & 0.81111 & 0.92106 & 0.89811 \\
\hline 7 & SABB & 0.92876 & 0.88302 & 0.87337 & 0.77927 & 1.00000 & 1.00000 \\
\hline 8 & SAMBA & 0.63316 & 0.86666 & 0.80830 & 0.79927 & 0.81303 & 0.82318 \\
\hline 9 & SHB & 0.85749 & 0.90388 & 1.00000 & 1.00000 & 1.00000 & 1.00000 \\
\hline 10 & SIB & 0.96499 & 0.79477 & 0.89504 & 0.78542 & 0.71127 & 0.73761 \\
\hline Mean Efficiency & & $\mathbf{0 . 8 1 9 1 3}$ & $\mathbf{0 . 8 5 0 0 2}$ & $\mathbf{0 . 8 6 7 2 6}$ & $\mathbf{0 . 8 3 0 9 0}$ & $\mathbf{0 . 8 6 1 6 7}$ & $\mathbf{0 . 8 6 7 8 4}$ \\
\hline
\end{tabular}

Table 2 .

\begin{tabular}{|c|l|c|c|c|c|c|c|}
\hline \multirow{2}{*}{ DMU No. } & \multirow{2}{*}{$\begin{array}{c}\text { DMU } \\
\text { Name }\end{array}$} & \multicolumn{7}{|c|}{ Input-Oriented VRS Efficiency } \\
\cline { 3 - 8 } & ANB & $\mathbf{2 0 0 3}$ & $\mathbf{2 0 0 4}$ & $\mathbf{2 0 0 5}$ & $\mathbf{2 0 0 6}$ & $\mathbf{2 0 0 7}$ & $\mathbf{2 0 0 8}$ \\
\hline 1 & AN2516 & 0.96918 & 0.98959 & 1.00000 & 1.00000 & 0.97664 \\
\hline 2 & ARB & 1.00000 & 1.00000 & 1.00000 & 1.00000 & 1.00000 & 1.00000 \\
\hline 3 & BAJ & 1.00000 & 1.00000 & 1.00000 & 1.00000 & 1.00000 & 1.00000 \\
\hline 4 & BSF & 1.00000 & 1.00000 & 1.00000 & 1.00000 & 1.00000 & 1.00000 \\
\hline 5 & NCB & 0.91388 & 0.93688 & 0.89230 & 0.68357 & 0.62319 & 0.66517 \\
\hline 6 & RYB & 0.63593 & 0.77378 & 0.84512 & 0.81273 & 0.92109 & 0.90154 \\
\hline 7 & SABB & 0.94250 & 0.91375 & 0.88533 & 0.77936 & 1.00000 & 1.00000 \\
\hline 8 & SAMBA & 0.63466 & 0.93996 & 0.91573 & 0.86765 & 0.91070 & 0.88773 \\
\hline 9 & SHB & 0.93576 & 1.00000 & 1.00000 & 1.00000 & 1.00000 & 1.00000 \\
\hline 10 & SIB & 1.00000 & 1.00000 & 1.00000 & 1.00000 & 0.94207 & 0.84560 \\
\hline Mean Efficiency & & $\mathbf{0 . 8 7 8 7 9}$ & $\mathbf{0 . 9 5 3 3 6}$ & $\mathbf{0 . 9 5 2 8 1}$ & $\mathbf{0 . 9 1 4 3 3}$ & $\mathbf{0 . 9 3 9 7 0}$ & $\mathbf{0 . 9 2 7 6 7}$ \\
\hline
\end{tabular}

Table 3 .

\begin{tabular}{|c|c|c|c|}
\hline Year & $\begin{array}{c}\text { Mean Technical Efficiency } \\
\text { (CRS) }\end{array}$ & $\begin{array}{c}\text { Input-Oriented Mean Technical } \\
\text { Efficiency } \\
\text { (VRS) }\end{array}$ & Mean Scale Efficiency \\
\hline 2003 & 0.8191 & 0.8788 & 0.9321 \\
\hline 2004 & 0.8500 & 0.9534 & 0.8916 \\
\hline 2005 & 0.8673 & 0.9528 & 0.9102 \\
\hline 2006 & 0.8309 & 0.9143 & 0.9087 \\
\hline 2007 & 0.8617 & 0.9397 & 0.9170 \\
\hline 2008 & 0.8678 & 0.9277 & 0.9355 \\
\hline
\end{tabular}

